Izabela SKRZYPCZAK Wanda KOKOSZKA ${ }^{2}$

\title{
ZRÓWNOWAŻONE METODY OCENY ZGODNOŚCI WYTRZYMALOŚCI BETONU NA ŚCISKANIE
}

\begin{abstract}
Artykuł prezentuje koncepcję weryfikacji jakości betonu konstrukcyjnego z zastosowaniem metod rozmytych. Nawiąuje do metod normowych i ukazuje ich nieścisłości. W normach projektowania konstrukcji betonowych lub żelbetowych wszystkie właściwości mechaniczne betonu są skorelowane z wytrzymałością charakterystyczną na ściskanie $f_{c k}$. Założenie, że wytrzymałość betonu jest wielkością losową oznacza, że możemy ją jednoznacznie zdefiniować i doświadczalnie sprawdzić, a rozważana wielkość stanowi określoną frakcję ogólną liczby wyników badań. Zakres w jakim te warunki są spełnione jest dyskusyjny. Zalecane normowe kryteria zgodności oraz procedury oceny wytrzymałości betonu i weryfikacji zgodności wytwarzanego betonu $\mathrm{z}$ wymaganiami stawianymi projektowanym klasom betonów w wielu przypadkach prowadzą do podejmowania niewłaściwych decyzji i strategii produkcji. Metody rozmyte stanowią propozycję wykorzystania metod alternatywnych do klasyfikacji betonu towarowego dla potrzeb konstrukcji inżynierskich, w tym obiektów budownictwa energetycznego, gdzie problem jakości materiału konstrukcyjnego jest szczególnie mocno związany z bezpieczeństwem ich użytkowania. Metody te w pełni wpisują się w ideę budownictwa zrównoważonego. Przypadkowe zaniżenie klasy betonu skutkuje odrzuceniem danej partii przez odbiorcę. Taka nienadająca się do wbudowania mieszanka betonowa jest wówczas traktowana jako odpad budowlany stojąc $\mathrm{w}$ sprzeczności $\mathrm{z}$ zasadami racjonalnego wykorzystania materiałów budowlanych i surowców mineralnych. Proponowana koncepcja weryfikacji jakości pozwala na zminimalizowanie ryzyka nieprawidłowego zaklasyfikowania partii betonu, czyli przypadkowego zawyżenia bądź zaniżenia jego klasy.
\end{abstract}

Słowa kluczowe: beton konstrukcyjny, wytrzymałość na ściskanie, jakość, zbiory rozmyte

\section{Wstęp}

Niepewności związane z oceną i klasyfikacją wytrzymałości betonu mają rozmyty, nielosowy charakter. Typową sytuacją, kiedy należy uwzględnić niepewność rozmytą jest ocena zgodności wytrzymałości betonu. Normowe kryte-

1 Autor do korespondencji: Izabela Skrzypczak, Politechnika Rzeszowska, ul. Poznańska 2, 35-959 Rzeszów, tel. +48 17 8651010, izas@ prz.edu.pl

${ }^{2}$ Wanda Kokoszka, Politechnika Rzeszowska, ul. Poznańska 2, 35-959 Rzeszów, tel. +48178651306, wandak@prz.edu.pl 
ria zgodności zalecane w PN-EN 206-1 [1] wykazują liczne wady [2,3]. Fakt ten jest powodem poszukiwania alternatywnych, rozmytych metod weryfikacji jakości betonu. $\mathrm{W}$ artykule przedstawiono $\mathrm{w}$ skrócie podstawowe pojęcia teorii zbiorów rozmytych oraz sformułowano procedurę weryfikacji jakości partii betonu do poszczególnych klas opartą na aproksymacji funkcji przynależności dla analizowanych klas betonu, wyznaczonych metodą rozmytą na podstawie zbudowania rozkładów brzegowych. Do analiz wykorzystano metodę symulacji losowej Monte Carlo oraz teorię zbiorów rozmytych.

\section{Podstawy teorii zbiorów rozmytych}

Jednym ze sposobów definiowania zbioru rozmytego jest wyznaczanie zbioru $A$ za pomocą funkcji charakterystycznej. W teorii zbiorów rozmytych, funkcja charakterystyczna przyporządkowuje każdemu $x \mathrm{z}$ obszaru rozważań $X$ wartość z przedziału [0; 1], a nie jak w przypadku zbiorów ostrych z dwuelementowego zbioru $\{0 ; 1\}$. Funkcja:

$$
\mathrm{A}=\left[\left(\mu_{\mathrm{A}}(\mathrm{x}), \mathrm{x}\right] \quad \mu_{\mathrm{A}}: X \rightarrow[0 ; 1]\right.
$$

nazywana jest funkcją przynależności. Jej wartość dla danego $x$ interpretuje się jako stopień, w jakim $x$ należy do zbioru rozmytego. Każdy element $x$ z obszaru rozważań $X$ należy do zbioru rozmytego $A$ zdefiniowanego w tym obszarze zpewnym stopniem przynależności (stopniem zaufania) określonym przez $\mu_{A}(x)$. Relacja przynależności elementu $x$ do zbioru $A$ może przyjąć jedną $\mathrm{z}$ postaci funkcji, które dzielone są na liniowe i nieliniowe. W praktyce stosuje się tylko kilka typów funkcji, głównie liniowych [3].

\section{Niepewności związane z oceną wytrzymałości}

Wyniki oceny zgodności wytrzymałości betonu na ściskanie można uznać za zdarzenia losowe, a kryteria zgodności za wielkości o rozmytych granicach. Kryteria zgodności, na podstawie których dokonuje się oceny jakości betonu mogą mieć charakter prawdopodobieństwa z jakim zdarzenie losowe znajdzie się w obszarze o rozmytych granicach (wg Zadeha) lub liczby rozmytej (o znanej funkcji przynależności, odpowiadającej prawdopodobieństwu, że zdarzenie będzie należało do pewnego przedziału (wg Yagera).

Normowe podwójne kryterium zgodności wytrzymałości betonu na ściskanie można zapisać za pomocą zbioru rozmytego zgodnie z formułą (2):

$$
f_{c}=\left[\mu_{f_{C}}(x), x\right], \mu_{f}: X \rightarrow[0,1]
$$

Gdzie: ${ }^{\mu_{f_{C}}(x)}$ jest funkcją przynależności przyporządkowującą każdemu elementowi zbioru wytrzymałości $x \in X$ stopień przynależności do zbioru rozmytego $f_{c}$ z przedziału $[0,1]$. 
Decyzja o zaliczeniu rozważanej partii betonu do projektowanej klasy zależy, z reguły, od spełnienia warunku narzuconego na wytrzymałość średnią z próby $f_{c m}$. Sporadycznie warunkiem decydującym jest ograniczenie wytrzymałości minimalnej w próbie $f_{c i}[2,3]$. Statystyczne kryteria zgodności wykazują wady, dlatego definiując funkcje przynależności do poszczególnych klas można odnieść się do zaleceń normowych oraz wiedzy eksperckiej. W bezpośredniej rozmytej metodzie kryteria zgodności są "wirtualnym ekspertem", dla których funkcje przynależności można zdefiniować kierując się zaleceniami normowymi m.in.: poziom kwantyla dla $f_{c k}$ na poziomie 0,05 [1] lub formułą dla średniej $f_{c m}=f_{c k}+8[4]$.

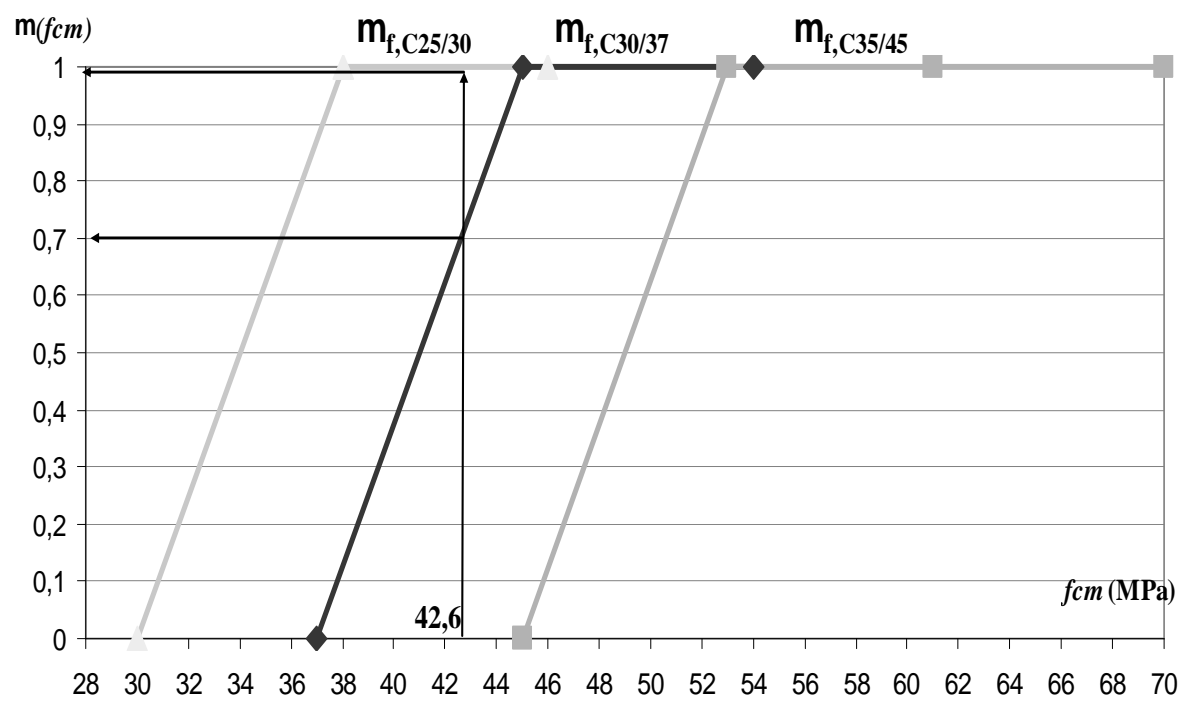

Rys. 1. Funkcje przynależności do poszczególnych klas dla rozważanej klasy betonu C30/37 i klas sąsiednich

Fig. 1. Functions of membership to respective classes for the considered concrete class $\mathrm{C} 30 / 37$ and neighboring classes

Kierując się zaleceniami normowymi zaproponowano przykładowe funkcje dla sklasyfikowania partii betonu o wytrzymałości średniej z próby 42,6 MPa. Na podstawie warunku normowego $\bar{x}_{n} \geq f_{c k}+4$ oraz wyznaczonych na podstawie zaleceń normowych funkcji przynależności (rys.1) można stwierdzić, że partie betonu, dla których wytrzymałość z próby wynosi 42,6 MPa można ze stopniem pewności 0,70 zaliczyć do klasy C30/37 lub ze stopniem pewności 1,0 do klasy betonu C20/25. Decyzja ta może być mniej lub bardziej ostrożna, w zależności od jakości produkowanego betonu oraz jej wpływu na zapewnienie bezpieczeństwa realizowanych konstrukcji. 


\section{Rozkłady brzegowe, aproksymacja funkcji przynależności}

W celu wyznaczenia funkcji przynależności dla rozważanych trzech sąsiednich klas zastosowano metodę rozmytą opartą na rozkładach brzegowych [4]. Pierwszym etapem metody rozmytej jest wyznaczenie parametrów rozkładów brzegowych; dlatego zdefiniowano zmienne losowe $\xi_{\text {i }} \eta$. Zmienna $\xi$ reprezentuje punkt rozdziału wartości wytrzymałości średniej betonu dla rozważanej i niższej klasy betonu, a $\eta$ punkt rozdziału rozważanej i wyższej klasy betonu. Założono, że para $(\xi, \eta)$ jest dwuwymiarową, normalną zmienną losową, dla której można wyznaczyć rozkłady brzegowe $p_{\xi}\left(f_{c m}\right)$ i $p_{\eta}\left(f_{c m}\right)$ zmiennych losowych $\xi \rightarrow N\left(m_{\xi}, \sigma_{\xi}\right)$ i $\eta \rightarrow N\left(m_{\eta}, \sigma_{\eta}\right)$. Dysponując funkcjami przynależności wytrzymałości średniej betonu na ściskanie dla różnych klas betonu, można określić stopień przynależności wartości rozważanej partii betonu do różnych klas. W zależności od wartości $\mu_{C}\left(f_{c m}\right)$ można podjąć decyzję o zaliczeniu partii betonu do odpowiedniej klasy.

\section{Przykład zastosowania rozmytych kryteriów zgodności}

Normowe podwójne kryterium zgodności wytwarzanej partii betonu z projektowaną klasą dla próby o liczebności $n=3$ można zapisać w postaci (3):

$$
\left.\begin{array}{l}
f_{c m} \geq f_{c k}+4 \\
f_{c i} \geq f_{c k}-4
\end{array}\right\}=C
$$

Charakterystyka testowa $C$ jest wielkością rozmytą o funkcji przynależności $\mu_{C}\left(f_{c m}\right)$, którą można wyznaczyć dla określonych klas betonu na podstawie rozkładów brzegowych oraz zdefiniowanych funkcji przynależności. Dla normowych kryteriów zgodności zalecanych w [1] wykonano obliczenia generując 100000 grup liczb losowych o liczebności $n=3$ zgodnych z rozkładem normalnym, losując klasę betonu (beton trzech sąsiednich klas $\mathrm{C}_{\mathrm{i}-1}, \mathrm{C}_{\mathrm{i}}, \mathrm{C}_{\mathrm{i}+1}$-jednakowe prawdopodobieństwo wyboru 1/3), odchylenie standardowe oraz wadliwość. Do generowania liczb losowych o standardowym rozkładzie normalnym posłużono się metodą Monte Carlo. Zbudowano tablicę funkcji rozkładu prawdopodobieństwa wektora losowego $(\xi, \eta)$ i wyznaczono histogram rozkładów brzegowych, sumując wiersze i kolumny: pierwszy (suma wierszy)- klasyfikując według rozważanej i niższej klasy betonu, drugi (suma kolumn) klasyfikując według rozważanej i wyższej klasy betonu. Wykresy funkcji gęstości rozkładów brzegowych prawdopodobieństwa $\mathrm{p}_{\xi}\left(\mathrm{f}_{\mathrm{cm}}\right)$ i $\mathrm{p}_{\eta}\left(\mathrm{f}_{\mathrm{cm}}\right)$ były podstawą wyznaczenia funkcji przynależności wytrzymałości średniej betonu na ściskanie do poszczególnych klas betonu [3]. Na podstawie przeprowadzonej symulacji dla betonu klasy C30/37, generując 100000 grup liczb losowych o liczebności $n=3$ zgodnych z rozkładem normalnym oszacowano funkcje gęstości rozkładów brzegowych oraz rozmyte funkcje przynależności wytrzymałości średniej betonu na ściskanie do poszczególnych klas betonu (trzech sąsiednich klas betonu). 
Rozważania przeprowadzono dla betonu klasy C30/37 uzyskując następujące oceny parametrów rozkładu brzegowego zmiennej losowej $\xi \rightarrow \mathrm{N}\left(\mathrm{m}_{\xi}, \sigma_{\xi}\right)$, tzn. punkt rozdziału dla betonu klasy $\mathrm{C} 20 / 25$ oraz $\mathrm{C} 30 / 37, \mathrm{~m}_{\xi}=32,02 \mathrm{MPa}$ oraz $\sigma_{\xi}=3,31 \mathrm{MPa}$. Parametry rozkładu brzegowego zmiennej losowej $\eta \rightarrow \mathrm{N}\left(\mathrm{m}_{\eta}\right.$, $\sigma_{\eta}$ ) punktu rozdziału dla betonu klasy C30/37oraz C35/45, oszacowano jako $\mathrm{m}_{\eta}$ $=34,88 \mathrm{MPa}$ i $\sigma_{\eta}=2,17 \mathrm{MPa}$.

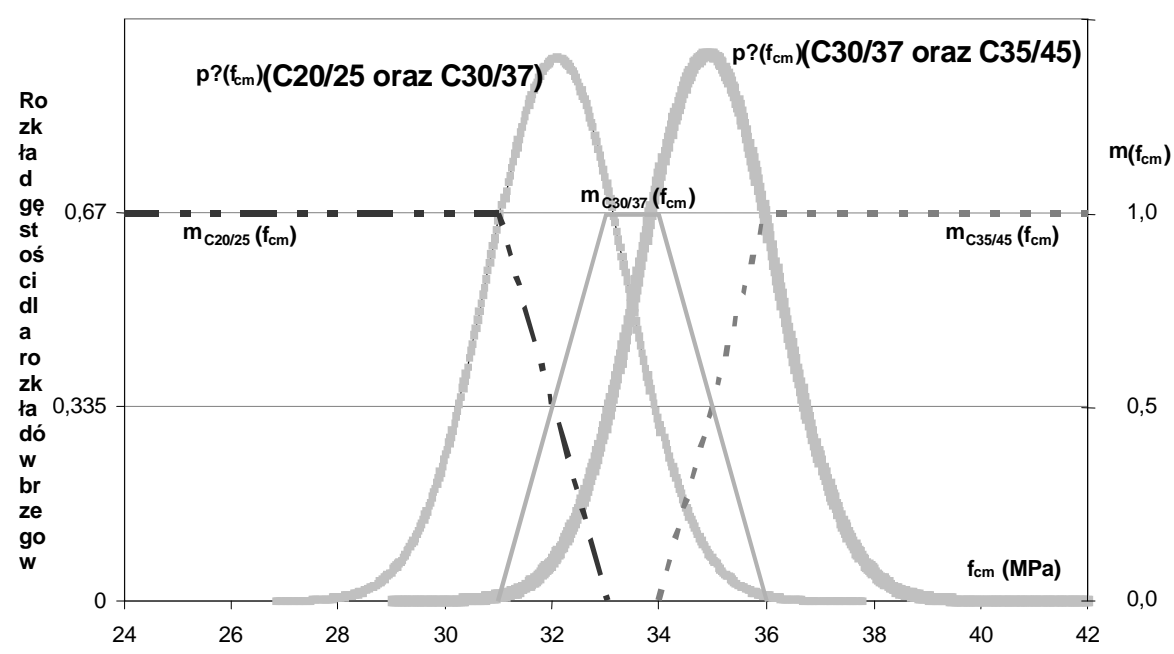

Rys. 2. Funkcje przynależności do poszczególnych klas oraz funkcje gęstości rozkładów brzegowych dla rozważanej klasy betonu C30/37 i klas sąsiednich

Fig. 2. Functions of membership to respective classes and density functions of marginal distribution for the considered concrete class C30/37 and neighboring classes

Funkcje gęstości nachodzą na siebie co świadczy o zbyt dużej liczbie klas proponowanych przez normę, co utrudnia jednoznaczne zakwalifikowanie do poszczególnych klas. Na podstawie wyznaczonych funkcji przynależności można stwierdzić, że partie betonu dla których wytrzymałość średnia z próby mieści się w przedziale od 32,8 MPa do 33,9 MPa można bez wątpliwości zaliczyć do klasy C30/37. W przypadku, gdy partie betonu mają średnią wytrzymałość na ściskanie z przedziału $(32 ; 32,8)$ MPa to produkowany beton można na pewno zaliczyć do betonu klasy $\mathrm{C} 20 / 25$ lub ze stopniem zaufania odpowiednio od 0,5 do 1,0 do klasy betonu C30/37. W sytuacji, gdy średnia wytrzymałość w partii betonu należy do przedziału od 33,8 do 35,0 MPa można ją zakwalifikować bez wątpliwości do klasy C30/37 lub ze stopniem pewności od 0,0 do 0,5 do klasy C35/45.

\section{Wnioski}

Metoda rozmyta zastosowana do klasyfikacji betonu wykazała, że obecnie obowiązująca normowa klasyfikacja betonu zawiera zbyt wiele klas betonu o rozkładach w dużej mierze nachodzących na siebie. Oznacza to, że stosowane kryteria normowe są "mało czułe" i mogą prowadzić do przypadkowego zaniże- 
nia lub zawyżenia klasy betonu. Ma to szczególne znaczenie w przypadku betonowych konstrukcji obiektów przemysłowych takich jak silosy, kominy, mosty, energetyczne budowle wodne oraz fundamenty urządzeń energetycznych. Klasyfikacja zastosowanego (wbudowanego) betonu ma poważny wpływ na niezawodność, trwałość i bezpieczeństwo eksploatacyjne tego typu konstrukcji. Metody rozmyte umożliwiają uwzględnienie niekiedy przeciwstawnych wymagań bezpieczeństwa, jakości, ekonomii, ekologii. Uwzględnienie powyższych wymagań jest możliwe poprzez ustalenie stopnia przynależności mniejszego od jedności dla rozważanej klasy betonu.

\title{
Literatura
}

[1] PN-EN 206-1: 2003. Beton. Część 1: Wymagania, właściwości, produkcja i zgodność, PKN.

[2] I. Skrzypczak, Sz. Woliński, Influence of distribution type on the probability of acceptance of conformity criteria for concrete strength, Archives of Civil Engineering 53, 3, 2007, s. 479-495.

[3] I. Skrzypczak I., Analiza kryteriów oceny jakości betonu oraz ich wpływu na ryzyko producenta i odbiorcy, Oficyna Wydawnicza PRz, Rzeszów 2013.

[4] PN-B-03264: 1999 Konstrukcje betonowe, żelbetowe i sprężone. Obliczenia statyczne i projektowanie.

\section{SUSTAINABLE METHODS OF CONFORMITY ASSESSMENT OF THE CONCRETE COMPRESSIVE STRENGTH}

\begin{abstract}
S u m m a r y
The article presents the concept of concrete quality verification with use of fuzzy methods. It refers to the code methods and shows inaccuracies od them. designing codes of concrete or reinforced concrete structures all concrete mechanical properties are correlated with the characteristic compressive strength $f_{c k}$. The assumption that concrete strength is a random quantity, means that we can define it clearly and verify empirically, and the considered quantity is a specified fraction of the total number of tests results. The range including fulfillment of these conditions is questionable. Recommended normalized compliance criteria, procedures of the strength evaluation and verification of compliance of produced concrete with designed concrete class in many cases lead to wrong decisions and improper production strategies Fuzzy methods are proposal of alternative methods application for the classification of ready-mixed concrete for needs of civil engineering structures, including power constructions, where the problem of the material quality is strongly related to their safety. These methods are fully matched with the idea of sustainable construction. Accidental understating class concrete results in rejection of the lot by the recipient. Such unsuitable for building concrete mix is then treated as a waste and is in contradiction with the principles of rational use of building materials and mineral resources. The proposed concept of concrete quality verification allows to minimize the risk of incorrect classification of concrete batch and prevents overstatement or understating of the class.
\end{abstract}

Keywords: structural concrete, compressive strength, quality, fuzzy sets

Przestano do redakcji: $10.12 .2014 \mathrm{r}$.

Przyjęto do druku: 22.06.2015 r.

DOI:10.7862/rb.2015.69 